\title{
OBSTETRIC ANALGESIA AND ANAESTHESIA- THE CURRENT SCENE
}

\author{
J. Selwyn Crawford, M.B., Ch.B., D.A., F.F.A.R.C.S. \\ Deputy Director and Leverhulme Research Fellow, Research Department of Anaesthetics, Royal College of \\ Surgeons of England, Lincoln's Inn Fields, London, W.C.2
}

THE PAST two decades have seen considerable advances in the techniques of obstetric analgesia and anaesthesia, and an equally marked change in the general philosophy which governs the approach to these subjects. The latter change has, in major part, resulted from the fact that with the steep decline in maternal and perinatal mortality and morbidity consequen't upon obstetric complications, the dangers to mother and child inherent in ill-conducted and poorlychosen techniques of pain relief become more easily apparent. The tenor of practice in Britain has further been modified as a consequence of the increasing incidence of hospital, as distinct from domiciliary, deliveries. A judioial review of all the techniques of obstetric analgesia and anaesthesia would be of monograph length (Crawford 1965 a). This paper will be concerned only with a discussion of those drugs and techniques which merit retention in the field of clinical practice.

\section{Relief of Distress During Labour \\ Training, Assurance, Comfort}

There seems to be little doubt that a wellconducted "preparation for labour" which forms part of the ante-natal supervision, is of considerable benefit to the majority of women who are exposed to this therapy. What is in doubt is whether or not the precise form of tuition is of any significance in deciding the outcome.

There are now several "schools" of preparations for labour. The first of these to achieve prominence was that of Dick-Read (Dick-Read, 1960), which emphasized that the most effective way in which the pain of labour may be forestalled is by teaching the patient how to relax fully. Dick-Read's basic assumption was that pain was engendered by tension, or fear, and that if the pregnant women were taught to anticipate the events of labour and delivery, and to associate the process with a feeling of satisfaction, the feature of pain would be eliminated. A more deterministic school of thought has its roots in French (Vellay, 1960) and Russian (Nikolayev, 1964) medical practice, and is becoming increasingly popular in Britain and the United States (Bonstein, 1958). The "psychoprophylactic method" of this school owes much to the teachings of Pavlov. The mothers-to-be are given a course of systemised lectures and demonstrations which aim to teach them to co-operate in a positive fashion during labour and delivery; the idea being, to put it rather crudely, that if they "ride with their uterus", as it were, labour and delivery will be facilitated and pain greatly reduced.

There are tremendous difficulties inherent in the comparative assessment of methods of pain relief under even the simplest circumstance, and these are greatly compounded when the situation is so emotionally charged as is that of the period of childbirth. An attempt to compare the adequacy of these two major systems woulde therefore be sterile. Each, it appears, has given relief and satisfaction to countless women Possibly this welcome result is related primarily to the fact that the patient gains confidence and ease from the knowledge that real concern is being shown for her welfare. Whatever the mode of action of these courses of instruction, there seems little doubt that their continuance and extension should be encouraged, and that all primigravidae, certainly, should be urged to attend one.

The technique of hypnosis lies on the fringe of this subject. The successful application of hypnosis has been reported to have been achieved in roughly $25 \%$ of patients chosen for study (Moya and James, 1960; Wahl, 1962). The incidence of complete or partial failure, the shortage of trained personnel, and the demands on the hypnotist's time, have limited the popularity of this method.

An even more stark projection of the DickRead concept is that of "white noise" (Burt and Korn, 1964; Barbe and Sattenspiel, 1965). Here, the patien't is subjected, via a pair of ear-phones, to sound of an intensity and pitch which distracts her attention from pain-provoking stimuli. This, possibly the ultimate in sub-noxious forms of distraction, has found favour in only a few centres. 
Finally, the importance of the mundane must be stressed. There should be little need to emphasize that an environment of gloom and austerity is unlikely to help the patient to achieve ease and comfort. The first-stage room should be bright and relaxing; furnished with sensibly designed chairs, and provided with television and appropriate contemporary reading matter (again-distraction). The value of the uninhibited attendance of the husband throughout his wife's labour and delivery is becoming increasingly appreciated, and it is accepted that the benefits derived are greater if the husband, too, has received tuition during the earlier months of his wife's pregnancy. In the last analysis, however, the patient will look to her nurse for the greatest support. A competent, unharassed mid-wife who has time to chat with the patients is the greatest boon in normal childbirth.

\section{Drugs}

All drugs which cross the "blood-brain barrier" must be considered as having the potential of traversing the placenta. Characteristically, these agents are highly lipid-soluble and are poorly ionized in blood. As all analgesics, sedatives and tranquilisers are able to reach the brain tissue, they must also be able with ease to pass from mother to foetus. Thus any drug which is administered systemically to relieve discomfort during labour will in some measure affect the foetus. It is highly likely that, in the case of all such agents, the interval between the time of administration of the drug to the mother and the time when an appreciable amount reaches the foetus is dependent solely upon the method of administration. For a given dosage, the more rapidly the drug is introduced into the maternal blood the more rapidly will it reach the foetus. Furthermore, it appears to be true to state also (Crawford and Rudofsky, $1965 \mathrm{a}$ and $\mathrm{b})$ that the quicker the rate of entry of the agent into maternal blood, the greater will be the portion of the dose which is transferred to the foetus. Thus drugs which are given by inhalation, and those which are injected intravenously as a concentrated solution, reach the foetus in appreciable amount within a minute or two of administration, and, in the case of the latter route, far more is passed to the foetus than is the case if the drug is given intramuscularly.

A survey of what is known regarding the parameters of the passage of individual drugs which are of special interest to the anaesthetist was recently published (Crawford, $1965 \mathrm{a}$ ), and there seems little point in repeating it here. However, it is worth noting the following recently-gathered additions to the list:

Methohexitone has been identified in cord blood obtained 1-2 minutes subsequent to the intravenous administration of the anaesthetic to the mother (Marshall, 1964).

It has been shown that pethidine reaches the foetus within two minutes of the intravenous administration to the mother: during the 3-4 hours subsequent to the intramuscular adminisration of this narcotic to the mother, the foetus receives slightly less than one per cent of the given dose (Crawford and Rudofsky, 1965b).

Following the intravenous administration of promazine to the mother, the drug may be identified in foetal blood within 2 minutes, and the maximum level of concentration is achieved within 2-3 minutes (Crawford and Rudofsky, 1965c).

Magnesium sulphate readily crosses the placenta, and the levels of concentration in maternal and cord blood are roughly equal at all times subsequently (Flowers, 1965).

When lignocaine is used to provide an epidural block, the analgesic appears in cord blood, where the level of concentration is said to be $45-80 \%$ of that in maternal venous blood sampled at the time of delivery (Morikawa, Kaneko and Muira, 1963; Beckett, Boyes and Parker, 1965).

It is assumed that reserpine passes from mother to foetus; the assumption is based upon recognition of the clinical condition of the neonate, seen with fair regularity when the mother had received reserpine: the infant has a nasal congestion and discharge, and must be treated with a nasal decongestant. (Budnik, Leihen and Hoech, 1955).

Bromosulphthalein, which is used commonly in a test of liver function, does not cross the placenta (Tindall and Beazley, 1965).

Finally, it is of interest to note that, despite the absence of nervous tissue in the placenta, the placental vessels contain alpha- and betareceptor sites. (Mancini and Gautieri, 1965).

Recent years have seen a marked reduction in the quantity of drugs prescribed during the course of a labour. It is now generally appreciated that sedatives-for example, the barbiturates - are better witheld, except when the patient is in very early labour and requires a restful night's sleep. Barbiturates are still administered as part of the routine treatment of a severely hypertensive patient during labour, but the merit of this form of therapy is open 
to considerable speculation. The metabolism and excretion of most barbiturates is a lengthy process, to be measured in days rather than in hours, and the neonate is further handicapped in this regard by a relative deficiency in its ability to detoxicate the compounds. Thus the salvage rate of foetuses who are already at risk due to placental insufficiency is likely to be diminished by the reliance upon barbiturates as a therapeutic measure.

Analgesia is rarely required during the early phase of established labour. General nursing care, incorporating reference to the ante-natal tuition, and whenever possible the sympathetic support of the attendant husband, should help the patient successfully through this period. If the mother is very apprehensive, a tranquillizer should be given. The drug must be given by injection, as absorption from the gastrointestinal tract is most unreliable during labour. At the present time, majority preference is given probably to a phenothiazine derivativefor example, promazine (Sparine) $50 \mathrm{mg}$.- but there is probably little important difference between each of the variety of tranquillisers available for this purpose. An exception to this generalization is provided by scopolamine which, although retaining some of its longestablished popularity, is finding increasing disfavour because it tends to make a substantial proportion of patients unmanageable.

As labour progresses, many patients (though relatively fewer of those who have had an adequate course of ante-natal tuition) will require a pain-reliever. The drug of choice in this context is pethidine. Morphine is not to be recommended, because of its quality as a sedative - and response to this activity is undesirable in both mother and child. Other available analgesics have yet to prove their worth as potential displacers of pethidine from its established popularity.

There is little doubt that the administration of pethidine during labour increases the chances that the infant will be depressed at delivery (Shnider and Moya, 1964; Kliger and Nelson, 1965; Crawford, 1966a). The peak incidence of depression is related to the time elapsing between administration of the drug and delivery of the infant and is dependent upon the mode of administration, though in the case of the usually-employed intramuscular injection, neonatal depression is more likely to occur if the drug was given 1-3 hours prior to delivery than if the interval were longer or shorter than this. There is still considerable debate regarding the efficiency of the narcotic antagonists in combating pethidine-induced neonatal depres-⿳亠丷厂巾 sion. As the resultant of the interaction betweenz narcotic and antagonist, when both drugs are ${ }_{\circ}^{\circ}$ given directly to the adult subject, remains toc. be finally elucidated (Foldes, Duncalf, Davidson, Yun and Schapira, 1964; Campbell, Masson $\stackrel{0}{\circ}$ and Norris, 1965), it is hardly surprising that? many clinicians are unconvinced of the value of the antagonist in obstetric practice. The present writer can only state his conviction 0 that the way of safety lies with the invariables accompaniment of pethidine with levallorphan $\vec{\circ}$ tartrate (Lorfan), in an 80:1 ratio.

There is some suggestion (Misrahy, Beran $\vec{\omega}$ and Prescott, 1963; Crawford, 1965b) that the depressant agents which reach the foetus vias the placenta induce intrauterine foetal asphyxia $\stackrel{3}{-}$ and thus can cause harm even before the respiratory depressant effect of the drugs sub-i sequent to delivery can be manifest. Further, there is some good evidence that the neonater is relatively more sensitive to these agents thano is the adult-although recently Way, Costley? and Way (1965) have demonstrated that while this is true of morphine, it might not be so in the case of pethidine.

Consideration of all these points leads to the conclusion that drug therapy during labola must be kept to a minimum in order to safeguard the well-being of the infant. Advances ins the care and understanding of the obstetrico patient during her pregnancy and labour, to $\frac{0}{2}$ gether with the considerable rise in the standard 8 of living in the Western world, have produced a dramatic fall in the rate of perinatal mortality 3 and morbidity during recent years. Previously, the deleterious effects of such factors as ex? cessive drug therapy passed unnoticed, becauseo of the vastly greater havoc wrought by in 3 . adequate supervision, serious obstetric pathology? and socio-economic distress. It must be accepted now that in order further to increase the excellence of obstetric care, serious attention must be paid to what was, before, a relativelys insignificant detail. Additionally, as perfection is approached, it becomes more difficult to de monstrate conclusively the positive value of any measure proposed to reduce further the hazard to the neonate. It is likely that only well conducted biochemical studies will provide data of significance in this regard, and studies of this nature are as yet few and far between? However, the evidence so far collected strongly suggests that, during the coming decade, clinic:ians will be persuaded that in order to make of further substantial reduction in the inoidence of perinatal morbidity, they will be obliged to 
follow the pattern already established in many obstetric centres of note, and to reduce drastically the quantity of drugs administered to a patient in labour.

When pethidine or a tranquillizer is given during labour, it is preferable to make the initial dose relatively high, so that the patient's confidence in the efficiency of the drug may be gained. The first dose of pethidine could be $100 \mathrm{mg}$. (given together with Lorfan 1.25 mg.), and subsequent doses should rarely need to exceed $50 \mathrm{mg}$., at intervals of not less than 3-4 hours. If a tranquillizer (for example, Sparine) was not administered during the early phase of labour, it is often as well to give a dose (Sparine $50 \mathrm{mg}$.) at the same time as the first injection of pethidine-all three drugs, pethidine, Lorfan and Sparine, may be administered as a combined injection. Subsequent alternate doses of pethidine may then be accompanied by $25 \mathrm{mg}$. Sparine, although the circumstance that three doses of pethidine will be required during a labour should arise only in the case of a primigravid patient.

\section{Local Analgesia}

Epidural block, administered via either the lumbar or the caudal route, has not achieved popularity in Britain, probably because the technique demands an increased degree of medical supervision of the patient, and also its use raises the incidence of forceps-aided delivery. However, there are strong arguments in favour of the use of this method of providing analgesia, and there are classes of patients for whom it might well be considered to be the method of choice. If vaginal delivery of a patient suffering from one of the following complications is to be undertaken, continuous epidural block is admirably suited to the conduct of the case: severe hypertension; acquired or congenital heart disease of more than a mild grade of severity; cerebro-vascular disease; history of recent abdominal operation; hepatic failure.

Effective mastery of the technique requires reasonably constant practice, and so if it is planned to use the method when any of the indications noted above is encountered, the technique should be relatively frequently $\mathrm{em}$ ployed in the routine treatment of the normal patient. When an epidural block is used during labour, the continuous technique-utilizing an in-dwelling catheter-is always to be preferred to the method of repeated "single-shot" injections. Use of the lumbar route rather than the caudal involves a much lower failure rate in skilled hands.

The use of paracervical block was advocated many years ago in Western Europe, but has recently gained popularity in the United States (Kobak, Sadove and Kobak, 1963; Zourlas and Kumar, 1965; Brown, Engel and Douglas, 1965). The technique is simple and highly effective. It consists of injecting a small amount of local anaesthetic solution ( $8-10 \mathrm{ml}$. of $1 \%$ lignocaine) into the base of each broad ligament, thereby achieving a block of the sensory nerves supplying the uterus and cervix. If the block is initiated only after labour has become well established, the subsequent progress of labour is not delayed (this proviso applies equally well to the use of epidural block and to the systemic administration of depressant drugs). Although the use of implanted catheters to permit the repetitive injections of analgesia solution has been advocated (Baggish, 1964), it seems that this must introduce an increased hazard of infection, and preferentially a single-shot technique should be used. (Dennis, 1964).

The block will give relief for approximately one hour. It does not usually obtund the bearingdown impulse and the perineal pain of the second-stage of labour, so that if the latter effects are required, a pudendal block should be given after the cervix has become fully dilated.

The only drawback to paracervical block which is of any real consequence lies in its propensity to produce foetal bradycardia. This response almost certainly reflects the effect of the injected solution upon the main uterine arteries. Although one study (Pitkin and Goddand, 1963) has suggested that the inclusion of adrenaline in the solution does not increase the incidence of foetal bradycardia, the fact that the usefulness of this adjunct depends upon its ability to cause vasoconstriction argues against advocating its employment when instituting a paracervical block.

The merits of paracervical block are well recognised. Full evaluation of the demerits of the technique, specifically with reference to the effects upon the foetus, is not yet established.

\section{Inhalation Agents}

Trilene and nitrous oxide continue to be the two agents of outstanding popularity as intermittent inhalational analgesics. Trilene, administered with the aid of a Central Midwives Board (C.M.B.)-approved apparatus, has not succeeded in ousting nitrous oxide from its 
pre-eminent position in this field. Whether administered in the statutorily approved "high concentration" $(0.5 \%$ in air) or "low concentration" $(0.33 \%)$, trilene does have the propensity of making a considerable proportion of patients rather more drowsy than is desirable during the second-stage. Further, there is a spreading convicition that if trilene is exhibited to the mother for an hour or longer prior to delivery, the likelihood that the neonate will be depressed is markedily increased: evaluation of this impression is lacking, because of the difficulties inherent in assessing the relative importance of the factors which contribute to depression of the newborn. On the other hand, of the two agents under consideration, trilene is the more effective analgesic, and thus the choice should be tailored to suit the individual patient.

Respecting nitrous oxide, much uneasiness has been engendered recently respecting the inadequacy of the equipment in current use (Nainby-Luxmore, 1964; Moir and Bisset, 1965). Despite the apparent innocuousness of the "gas and air" method of analgesia as practiced during the past 30 years, the administration of a mixture containing, at best, only $10 \%$ oxygen, is not an exercise which appeals to the critical mind of today. The observation that a considerable proportion of the machines in current use deliver actually much less than $10 \%$ oxygen has greatly encouraged the popularity of a new technique. Cylinders containing a 50:50 mixture of nitrous oxide and oxygen (Gale, Tunstall and Wilton-Davies, 1964) are now available, and their use by midwives has been approved by the C.M.B. The latter body has also given its approval to the Lucy Baldwin gas and oxygen machine (McAneny and Doughty, 1963), a modification of an older apparatus (the Walton Five). The Lucy Baldwin may be set to deliver oxygen in concentration ranging from $30 \%$ in nitrous oxide, up to $100 \%$. It is expected that, in time, gas and oxygen analgesia will supplant completely the gas and air technique.

\section{Anaesthesia for Operative Obstetrics Caesarean Section}

British practice continues to favour general anaesthesia over regional block for Caesarean section, irrespective of the indication for the operation. Evidence accumulated during the past few years tends to strengthen the conviction that the choice is a wise one only if the technique adopted conforms to the best modern standards. Basically, the method of general anaesthesia for any Caesarean section should气 consist of: induction with a small dose of thiopentone and a relaxant drug; endotracheal 8 intubation; Maintenance of anaesthesia with a nitrous oxide-oxygen mixture supplied by inter- $\vec{\Rightarrow}$ mittent positive pressure with the assistance of a relaxant. Subsequent to delivery of the infant, $\frac{\mathrm{C}}{\mathrm{O}}$ further analgesia may be promoted with pethi- $\bar{c}$. dine given intravenously intermittently, or with ${ }_{\mathbb{D}}$ cyclopropane. This basic scheme may be modified slightly to meet certain unusual cir-es cumstances. For example, for the toxaemic $\vec{\circ}$ patient who has been receiving large doses of barbiturates prior to operation, cyclopropane ${ }_{\mathcal{O}}$ should be substituted for thiopentone as theo induction agent (anaesthesia should thereafter be maintained with nitrous oxide). Cyclopropane should similarly be substituted for thio-? pentone in cases of massive ante-partumo haemorrhage if surgery is to start before restitu- $\dot{\omega}$ tion of the maternal blood pressure, and in ${ }^{\sigma}$ cases of porphyria. The two outstandinglyo important aspects of the technique are endo-tracheal intubation and the use of nitrous oxide $ᄃ$ for maintenance. General anaesthesia should never be administered to an obstetric patient $\vec{\circ}$ for delivery of the infant or of the placenca without the employment of intubation-t sooner this rule is universally adopted, tre. more rapidly will fall the incidence of maternal morbidity and mortality referable to anaes-o thesia. The use of nitrous oxide for maintenance precludes the need for any undue haste by the $\stackrel{\mathbb{Q}}{2}$ obstetrician to deliver the infant, unless the $\overrightarrow{\overrightarrow{0}}$ pathology involved demands it. If a more 3 depressant inhalational agent is used, there is no doubt that the chances of inducing neonatal depression will increase as the time elapsing 흑 between induction and delivery lengthens. Un- doubtedly, the incidence of drug-induced depres- $\frac{5}{3}$ sion amongst cases delivered within, say, 5. minutes of the start of anaesthesia, will be low. 을 However, whilst the tempo of British surgery is not quite as slow as that seen generally in the United States (where this factor has certainly $\frac{\text { ? }}{2}$ played in important part in determining the preference for regional block over general or anaesthesia for section), the usual induction- $N$ delivery interval is within the range 10-20 N minutes, and in these circumstances the use ${ }_{\sigma}^{\omega}$ of cyclopropane or any agent other than nitrous

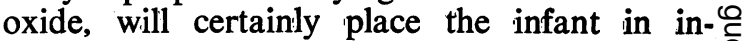
creased jeopardy. When the "recommended $\stackrel{\Phi}{\Phi}$ technique" (thiopentone $250 \mathrm{mg}$., plus succinylcholine $100 \mathrm{mg}$.- intubation-succinylcholine infusion and 50:50 nitrous oxide- $\mathbb{\mathbb { D }}$ oxygen by intermittent positive pressure with $\stackrel{\mathbb{D}}{\mathbb{D}}$ 
moderate hyperventilation-see Crawford, 1965a) is used, the induction-delivery interval may be as short or as long as the operative conditions dictate, without introducing the dangers of either drug-induced depression or of an exaggerated degree of neonatal asphyxia. (Crawford, 1962a; Crawford, 1966b).

The dose of thiopentone required will be in the range $200-250 \mathrm{mg}$.- - rarely $300 \mathrm{mg}$. will need to be given. The writer's preference is to use succinylcholine for relaxation (Crawford, 1965a), administering the drug by infusion. The latter is not an additional complication of the technique, for no section should be undertaken without having a drip set up-failure to observe this rule is reflective of grave administrative failure in the obstetric section of the anaesthesia department. Despite the observation, recently reported by Schnider (Schnider, 1965), that patients at term have a low serum cholinesterase activity, the present writer's experience is that reversal of a deplorising neuro-muscular blockade is not unusually delayed in these patients. The writer also prefers to employ a 50:50 mixture of nitrous oxide and oxygen, and to spend the minute prior to delivery "washingout" the nitrous oxide with $100 \%$ oxygen, for reasons detailed elsewhere (Crawford, 1965a).

It is probable that, from the point of view of the well-being of the infant, regional block is preferable to any technique of general anaesthesia which includes the use of an inhalational agent other than nitrous oxide for maintenance. The difference is probably of little significance when the induction-delivery (I-D) interval is very brief. or when an elective section is being undertaken on a perfectly healthy mother and foetus. However, the contrast becomes more striking when the factors of a prolonged I-D interval and an emergency situation (with intrauterine asphyxia) are introduced. The administration of an agent such as cyclopropane to an asphyxiated foetus should no longer be countenanced.

There is, however, a drawback inherent in the use of regional blockade which renders the method less satisfactory than the recommended technique of general anaesthesia. While, for obvious reasons, drug-induced neonatal depression does not occur under regional block analgesia whatever the extent of the I-D interval, prolongation of this interval is associated in systematic fashion with a gradual increase in the degree of asphyxia of the foetus (Crawford, 1965c). Almost certainly, this correlation reflects the fact that the vasopressor agent which is routinely given to maintain maternal blood pressure in the course of a regional block extending to the mid-thoracic region, reduces uterine blood flow by inducing an excessive vasoconstriction of the uterine vascular bed (Greiss and Crandell, 1965). It seems possible that there exists an independent mechanism which maintains uterine peripheral resistance (Lucas, Kirschbaum and Assali, 1965). The difficulty of administering precisely the amount of vasopressor required to restore uterine peripheral resistance to the pre-spinal level would appear to be insurmountable in clinical practice. Unfortunately, the answer to the problem does not lie in withholding altogether the vasopressor, as the resultant maternal hypotension is itself injurious to the foetus (Moya and Smith, 1962; Stenger, Andersen, De Padua, Eitzman, Gessner and Prystowsky, 1964), and this is especially so in cases in which the foetus is already at risk due to diminished placental reserve (Bieniarz, Fernadez-Sepulveda and Caldeyro-Barcia, 1965). It must therefore be accepted that, contrary to previously-held opinion, the duration of the I-D interval is of considerable importance to the well-being of the foetus when a section is carried out under regional block. In fairness it must be pointed out that the studies from which most of these data were derived were carried out with reference to spinal analgesia, but there seems little cause to doubt that the conclusions apply equally well to epidural block.

It has for long been appreciated that the dose of drug required to produce a satisfactory spinal block in a pregnant patient at term is considerably less than would be needed to induce a block of the same extent in a nonpregnant adult. Bromage (Bromage, 1962) has, more recently, conclusively demonstrated that a similar statement pertains to epidural block, and in an authoritative article he states that the dose required for a pregnant patient must be reduced by one-third from that which would be needed for a non-pregnant adult of the same age and height.

\section{Vaginal Delivery}

There is currently a welcome swing of opinion against the use of general anaesthesia for forceps delivery. Techniques of general anaesthesia, including the thiopentone-relaxant -nitrous oxide sequence, offer no advantage to the infant over regional block in the majority of cases, and the spinal and epidural forms of analgesia do not involve the hazard of interference with maternal cardiovascular dynamics. 
The all-important factor of concern, however, is that by excluding the use of general anaesthesia, the prospect of maternal aspiration of regurgitated gastric contents is virtually abolished. The tragic sequelae of the latter condition are still seen with far too great a frequency (Dinnick, 1964) and the implementation of any measure which may rationally be introduced to reduce the occurrence must be given full encouragement. The avoidance of general anaesthesia under almost any circumstance in domiciliary practice, and in all but a small, very well-defined group of circumstances in hospital practice, are two such measures.

The preferred technique for forceps delivery is pudendal block. This should be combined with bilateral ilio-inguinal nerve block and infiltration of the line of the proposed episiotomy (Crawford, 1965a) to provide with greater certainty, full perineal analgesia. It must be noted that if lignocaine (Xylocaine) is used, the total dose administered should not exceed $500 \mathrm{mg}$.

Spinal block ("saddle block") and epidural block will give analgesia as satisfactorily as pudendal block, and will also provide a more fully relaxed perineum, but neither of these methods has gained popularity in Britain. An alternative to pudendal block which is finding growing favour is "hypoaesthesia" (Crawford, 1965a). This consists of the slow intravenous injection of a mixture of pethidine, a narcotic antagonist and a tranquillizer. The solution is made up usually in $20 \mathrm{ml}$., and contains 150 $\mathrm{mg}$. pethidine, $2 \mathrm{mg}$. levallorphan, and $50 \mathrm{mg}$. promazine (Sparine). Less than the total quantity is given if the patient had received a considerable amount of the same or similar drugs during the previous few hours. The mother becomes quite drowsy 2-10 minutes after completion of the injection, but is rousable. She should be warned of the sequence of events which will follow. Immediately after the solution had been administered, the patient is placed into the lithotomy position, the skin preparation performed and the bladder catheterized. These manoeuvres will occupy sufficient time for the drugs to become effective. Local infiltration of the proposed line of the episiotomy is essential to the success of the method. Hypoaesthesia is admirably suited to a low forceps delivery with minimal rotation of the foetal skull, and also, in the majority of cases, to extraction of a retained placenta. Provided that the injection is given slowly, in the dilution advised, neither hypotension nor nausea will result. Neonatal depression will not be reflective of the use of hypoaesthesia. The mother is likely to have only a hazy recollection of her delivery, 3 and in the majority of cases there will be com- $\stackrel{\otimes}{\Omega}$ plete amnesia. The facts that this method. . entails the use of so little apparatus, demands $\vec{\Rightarrow}$ less practiced skill than does a pudendal block, and avoids the dangers of maternal regurgitation and aspiration, commends most highly its $\frac{\bar{m}}{\bar{m}}$ increasing application in domiciliary obstetrics. $\frac{\vec{\sigma}}{\nabla}$

Mention might usefully be made here of $\stackrel{\mathbb{D}}{\circ}$ halothane. This agent is an extremely effective is uterine relaxant, its efficiency in this respect $\vec{O}$ being superior to that of either ether or chloroform. Because of this property, the use of halo- $\vec{\omega}$ thane to anaesthetize a patient for delivery $\frac{}{0}$ of either the infant or the placenta introduces the possibility of promoting inefficient myometrial retraction with consequent postpartum $\stackrel{\overrightarrow{0}}{\mathrm{a}}$ haemorrhage. There are advocates of the use of halothane in a scheme of anaesthesia for forceps delivery (Stoelting, 1964; Wilson and $\stackrel{\circlearrowleft}{-}$ Vandewater, 1965) but in the writer's opinion $\circ$ this practice should be condemned (Crawford, 1962 b). For the obstetric patient the agent $c$ should be used only when uterine relaxation is $\underset{\sigma}{\vec{D}}$ a requirement of the surgical procedure. The $\overrightarrow{\overrightarrow{0}}$ indications therefore are: external cephali $\&$ version; a tightly contracted uterus which i terferes with delivery at Caesarean section; difficult internal version; if the obstetrician can not insert his hand into the uterus to perform a manual removal of the placenta. Halothane $\stackrel{\circ}{\circ}$ administration should cease as soon as the $\stackrel{\varnothing}{\circ}$ indication for it has passed, as the relaxation cannot safely be countered by oxytocics.

Local analgesia, with pudendal block, is being generally favoured for breech delivery. However, an anaesthetist should always be 흥 present lest his services are required for help with delivery of the after-coming head. Under such circumstance, preparation will have been made for a rapid induction of anaesthesia and endotracheal intubation, with the aid of thiopentone and succinylcholine injected via a previously inserted in-dwelling needle.

\section{Vomiting}

The inhalation of regurgitated material is the greatest hazard in obstetric anaesthesia, and it still claims, unnecessarily, several victims each year in Britain. The strict avoidance of general anaesthesia for all but a very small selection of vaginal deliveries should do much to diminish this toll. However, for these exceptions, and for the emergency cases of Caesarean section, other measures are required. These measures are basically organisational in 
character The diet of the patient in labourand especially of one (previous section, breech presentation, multiple pregnancy) who is "at risk"-must be strictly controlled. Food should be light, easily assimilated and non-fatty (Crawford, 1962a). Milk should be avoided. When labour has become well-established in the "high-risk" patient, and when a patient begins to present the picture of a protracted labour, all oral intake should cease, and an intravenous infusion should take its place. The anaesthetic apparatus should be in a state of readiness throughout each 24 hours, and when a patient "at risk" is admitted to the labour ward, the anaesthetist who will most likely be called to her delivery should be given fair warning so that he may take the appropriate steps without dangerous haste.

If there is any likelihood that the patient's stomach contains ingested material, gastric emptying must precede the induction of general anaesthesia excepting only when delay in delivery would invoke the gravest hazard for mother or infant. Gastric intubation continues to be practiced but it is neither the most pleasant nor the most efficient way of emptying the stomach. The present writer's advocacy of the use of apomorphine continues (Crawford, 1962a). A description of the method of its administration may be found in the cited reference. The point must be made, however, that even though steps have been taken to empty the stomach (by apomorphine-induced vomiting or by aspiration), the anaesthetist must never assume that the stomach is free from contents.* The presence of an efficient suction apparatus - switched on and ready for use-is mandatory at the time of induction of anaesthesia and prior to extubation at the end of operation. Anaesthesia should not be induced with the patient in the lithotomy position (delivery of an after-coming head is the one unavoidable exception to this rule). The advocates of head-up tilt and of head-down tilt each have good reasons to advance: the writer prefers to keep the table horizontal. If all precautions have been taken the patient may satisfactorily be induced while in the prone position, but if regurgitation is still much feared (and this will apply especially in the case of prolonged labour, for the ileus which frequently accompanies this condition may be responsible for re-filling the stomach subsequent to the preparatory measures), the right-lateral position, as advocated by Bourne (Bourne, 1962) has much to commend it.
In the unfortunate circumstance that aspiration of stomach contents does occur, prophylaxis against the acid-aspiration syndrome should be undertaken immediately. This should consist of the administration of hydrocortisone $(100 \mathrm{mg}$. intramuscularly immediately, followed by $50 \mathrm{mg}$. i.m. six-hourly for at least 24 hours), and antibiotics (Bannister, Sattilaro and Otis, 1961).

\section{REFERENCES}

Baggish, M. S. (1964): Continuous Paracervical Block, Amer. J. Obstet. Gynec., 88, 968.

BanNister, W. K., Sattilaro, A. J., and Otis, R. T. (1961): Therapeutic Aspects of Aspiration Pneumonitis in Experimental Animals, Anesthesiology, 22, 440.

Barbe, D. P., and Sattenspiel, E. (1965): Audioanalgesia in Labor and Delivery, Obstet. and Gynec., 25, 683.

Beckett, A. H., Boyes, R. N., and Parker, J. B. R. (1965): Determination of Lignocaine in Blood and Urine in Human Subjects Undergoing Local Analgesic Procedures, Anaesthesia, 20, 294.

Bieniarz, J., Fernandez-Sepulveda, R., and CalDEYRO-BARCIA, R. (1965): Effects of Maternal Hypotension on the Human Fetus II, Amer. J. Obstet. Gynec., 92, 832.

BonsteIN, I. (1958): Painless Childbirth. 1st ed., New York: Grune and Stratton.

Bourne, J. G. (1962): Anaesthesia and the Vomiting Hazard, Anaesthesia, 17, 379.

BROMAGE, P. R. (1962): Spread of Analgesia Solutions in Epidural Space and Their Site of Action: a Statistical Study, Brit. J. Anaesth., 34, 161.

Brown, E. O., ENGEL, T., and Douglas, R. E. (1965): Paracervical Block Analgesia in Labor, Obstet and Gynec., 26, 195.

BUDNIK, I., LEIHEN, S., and HOEH, L. (1955): Effects in the Newborn Infant of Reserpine Administered Antepartum, A.M.A. J. Dis. Child, 90, 286.

BURT, R. K., and KorN, G. W. (1964): Audioanalgesia in Obstetrics, Amer. J. Obstet. Gynec., 88, 361.

FOOTNOTE :

*Recently, G. Taylor and J. Pryse-Davies (Lancet, $1966, \mathbf{i}, 288$ ) have examined the practice, founded upon O. P. Dinnick's suggestion (Proc. roy. Soc. Med., 1957, 50, 547), that an antacid be administered regularly to a patient in labour with a view to reducing the severity of symptoms should regurgitation and aspiration occur. Taylor and Pryse-Davies report that pulmonary complications which are characteristic of the "acid-aspiration syndrome" are seen comparatively rarely when fluid of $\mathrm{pH}$ greater than 2.50 is instilled into the lungs. They further found that the oral administration of $14 \mathrm{ml}$. magnesium trisilicate mixture (B.P.C.) resulted in a lowering of gastric acidity to a $\mathrm{pH}$ above 2.50 for at least two hours. Colloidal aluminium hydroxide was not so effective in this respect. It is thus suggested that magnesium trisilicate mixture be given prior to the induction of general anaesthesia, as part of the pre-medication (and subsequent to gastric emptying, if the latter manoeuvre has been employed). In the opinion of the present writer, the routine two-hourly administration of the antacid to the patient "at risk" is to be commended. 
Campbell, D., Masson, A. H. B., and Norris, W. (1965): Clinical Evaluation of Narcotic and Sedative Drugs II. A Re-valuation of Pethidine and Pethilorfan, Brit. J. Anaesth., 37, 199.

Crawford, J. S. (1962a): Anaesthesia for Caesarean Section: Proposal for Evaluation with Analysis of a Method, Brit. J. Anaesth., 34, 179.

Crawford, J. S. (1962b): The Place of Halothane in Obstetrics, Brit. J. Anaesth., 34, 386.

Crawford, J. S. (1965a): Principles and Practice of Obstetric Anaesthesia, 2nd ed., Oxford: Blackwell.

Crawford, J. S. (1965b): Maternal and Cord Blood at Delıvery I, Biol. Neonat. (Basel), 8, 131.

Crawford, J. S. (1965c): Maternal and Cord Blood at Delivery II, Parameters of Respiratory Exchange: Elective Caesarean Section, Amer. J. Obstet. Gynec., 93, 37.

Crawford, J. S. (1966a): Maternal and Cord Blood at Delivery III, Parameters of Respiratory Exchange: Apgar score, Amer. J. Obstet. Gynec. In press.

Crawford, J. S. (1966b): Comparison of Spinal Analgesia and General Anesthesia for Elective Cesarean Section, Amer. J. Obstet. Gynec., 94, 858.

Crawford, J. S., and Rudofsky, S. (1965a): The Mode of Administration of Promazine as a Factor in Determining the Extent of Placental Transmission, Brit. J. Anaesth., 37, 310.

Crawford, J. S., and RudofSKY, S. (1965b): Placental Transmission of Pethidine, Brit. J. Anaesth., 37, 929.

Crawford, J. S., and RudofSky, S. (1965c): Placental Transmission and Neonatal Metabolism of Promazine, Brit. J. Anaesth, 37, 303.

DENNIS, K. J. (1964): Unilateral Parametritis following Paracervical Block, J. Obstet. Gynaec. Brit. Cwlth., 71, 797.

Dick-READ, G. (1960): Childbirth without Fear, 4th ed. London: Heinemann.

DinNiCK, O. P. (1964): Deaths Associated with Anaesthesia, Anaesthesia, 19, 536.

Flowers, C. E. (1965): Magnesium Sulfate in Obstetrics, Amer. J. Obstet. Gynec., 91, 763.

Foldes, F. F., Duncalf, D., Davidson, G. M., Yun, D. S., and Schapira, M. (1964): Comparison of the Respiratory and Circulatory Effects of Narcotic Antagonists, Anaesthesiology, 25, 95.

Gale, C. W., Tunstall, M. E., and Wilton-Davies, C. C. (1964): Pre-mixed Gas and Oxygen for Midwives, Brit. med. J., i, 732.

Greiss, F. C., and CRANDELl, D. L. (1965): Therapy for Hypotension Induced by Spinal Anesthesia during Pregnancy, J. Amer. med. Ass., 191, 793.

Kliger, B., and Nelson, H. B. (1965): Analgesia and Fetal Depression with Intravenous Meperidine and Propriomazine, Amer. J. Obstet. Gynec., 92, 850.

Kobak, A. J., Sadove, M. S., and KobaK, A. J. (1963) : Childbirth Pain Relieved by Combined Paracervical and Pudendal Nerve Block, J. Amer. med. Ass., 183, 931.

LuCAS, W., Kirschbaum, T., and Assali, N. S. (1965): Spinal Shock and Fetal Oxygenation, Amer. J. Obstet. Gynec., 93, 583.

Mancini, R. T., and Gautieri, R. F. (1965): Effect of Certain Drugs on the Perfused Human Placenta, V. J. pharm. Sci., 54, 1443.
Marshall, J. R. (1964): Human Antepartum Pla cental Passage of Methohexital Sodium, Obste Gynec., 23, 589.

MCANENy, T. M., and Doughty, A. G. (1963): Selfoadministered Nitrous-oxide/oxygen Analgesia in Obstetrics, Anaesthesia, 18, 488.

Misrahy, E. A., Beran, A. V., and Prescott, E. ? (1963): Effects of Drugs used in Pregnancy orit availability of Fetal Cerebral Oxygen, Anesthesi음 ology, 24, 198.

MoIr, D. D., and Bisset, W. I. K. (1965): An Assesseึ ment of Nitrous Oxide Apparatus Used for $\mathrm{Ob}$ 은 stetric Analgesia, J. Obstet. Gynaec. Brit. Cwlth ڤ్

72, 264.
Morikawa, S., Kaneko, S., and Miura, J. (1963) $\vec{\circ}$ Changes in the Blood Concentrations of Xylocaine $\vec{E}$ Administered through Various Routes in Man, $F a \xi_{\sigma}$ East J. Anesth., 4, 27.

MoyA, F., and JAMES, L. S. (1960): Medical Hypnosis for Obstetrics, J. Amer. med. Ass., 174, 2026.

MoyA, F., and SMITH, B. (1962): Spinal Anesthesidu for Cesarean Section, J. Amer. med. Ass., 179, 609

NAINBy-LuXmore, R. C. (1964): Further Hazards ogొ Gas and Air in Obstetrics, Anaesthesia, 19, 421. ஸ્

Nikolayev, A. (1964): Psychoprophylactic Prepara= tion of Pregnant Women for Parturition in the Soviet Union, J. Inter. Fed. Gynaec. Obstet., 2, 3?

Pitkin, R. M., and Goddard, W. B. (1963): Parae cervical Uterocervical Block in Obstetrics-a Con trolled, Double-blind Study, Obstet. and Gynec.Ф 21, 737.

ShNider, S. M. (1965): Serum Cholinesterase Actio̊t during Pregnancy, Labor and the Puerperiơn? Anesthesiology, 26, 335

SCHNider, S. M., and MoyA, F. (1964): Effect Meperidine on the Newborn Infant, Amer. $J$ ? Obstet. Gynec., 89, 1009.

Stenger, V., Andersen, T., De Padua, C., Eitz man, D., Gessner, J., and Prystowsky, H. (1964) ฉ Spinal Anesthesia for Cesarean Section, Amer. J $\overrightarrow{\overline{\hat{O}}}$ Obstet. Gynec., 90, 51.

Stoelting, V. K. (1964): Fluothane in Obstetric Anesthesia, Anesth. Analg., 43, 243.

Tindall, V. R., and Beazley, J. M., (1965): Assess:ment of Changes in Liver Function during NormaP Pregnancy - using Modified Bromosulphthaleip. Test, J. Obstet. Gynaec. Brit. Cwlth., 72, 717.

Vellay, P. (1960): Childbirth without Pain, lst ed London: Hutchinson, and Allen and Unwin.

WAHL, C. W. (1962): Contraindications and Limita-3 tions of Hypnosis in Obstetric Analgesia, Amer. $J_{0}$ Obstet. Gynec., 84, 1869.

Way, W. L., Costley, E. C., and Way, E. L. (1965): D Respiratory Sensitivity of the Newborn Infant to Meperidine and Morphine, Clin. Pharmacol. Ther. N
6, 454.

Wilson. K. B., and VANDEwater, S. L. (1965): N Halothane in Obstetrics: Five Years' ExperienceN Anesth. Analg., 44, 34.

Zourlas, P. A., and Kumar, D. (1965): Objective Evaluation of Paracervical Block on Humaro Uterine Contractility, Amer. J. Obstet. Gynec. 91, 217. 